\title{
Influence of minor additions of boron and zirconium on shape memory properties and grain refinement of a $\mathrm{Cu}-\mathrm{Al}-\mathrm{Mn}$ shape memory alloy
}

\author{
V. Sampath ${ }^{\text {a1 }}$ and U.S. Mallik ${ }^{2}$ \\ ${ }^{1}$ Department of Metallurgical and Materials Engineering, I.I.T. Madras, Chennai - 600036, India \\ ${ }^{2}$ Department of Mechanical Engineering, S.I.T, Tumkur-572103, India
}

\begin{abstract}
Cu-base alloys with 12.5 wt. \% $\mathrm{Al}$ and 5 wt. \% Mn with different amounts (0.05-2.00 wt.\%) of boron or zirconium were prepared by ingot metallurgy route. The alloy ingots were homogenized followed by step quenching so as to obtain a structure that is completely martensitic. They were subsequently characterized by optical emission spectrophotometry, differential scanning calorimetry and optical microscopy. The shape memory and superelastic properties of the alloys were studied by bend and tensile test. The present study brings to light that boron acts as a good grain refiner, resulting in a reduction of about $80 \%$ in grain size. While it also increases the transformation temperatures by $\sim 10^{\circ} \mathrm{C}$, it decreases the strain recovery by shape memory effect by $4 \%$, and that by superelasticity by $\sim 2 \%$. A comparison of the results of the alloy with B addition with that with $\mathrm{Zr}$ addition reveals that $\mathrm{B}$ is a better grain refiner for $\mathrm{Cu}-\mathrm{Al}-\mathrm{Mn}$ SMAs.
\end{abstract}

\section{Introduction}

A host of alloy systems exhibit shape memory effect (SME). , $\mathrm{Cu}-\mathrm{Al}-\mathrm{Ni}$ and $\mathrm{Cu}-\mathrm{Zn}$-Al shape memory alloys (SMAs) have been studied extensively over the years. Unlike Ni-Ti SMAs these copper-based shape memory alloys are easier to produce and process and are also less expensive. However, $\mathrm{Cu}-\mathrm{Al}-\mathrm{Ni}$ and $\mathrm{Cu}-$ $\mathrm{Zn}-\mathrm{Al}$ alloys in the polycrystalline state are brittle and cannot, therefore, be cold worked due to the high degree of order and high elastic anisotropy that are possessed by the high temperature parent phase $(\beta)$ [1]. The recent studies show that $\mathrm{Cu}-\mathrm{Al}-\mathrm{Mn}$ alloys with higher $\mathrm{Mn}$ contents exhibit excellent ductility since their parent phase with an L2 ${ }_{1}$ structure possesses comparatively a lower degree of order [2].

The $\beta$-phase phase in $\mathrm{Cu}$-Al-Mn SMAs is disordered and stable at high temperatures and transforms to martensite on quenching from the austenitizing temperature. The alloys go through a sequence of ordering reactions, $\beta(\mathrm{A} 2) \rightarrow \beta_{2}(\mathrm{~B} 2) \rightarrow \beta_{1}\left(\mathrm{~L} 22_{1}\right)$, on quenching.

Three different types of martensite, namely $\alpha_{1}$ ' (3R), $\beta_{1}$ ' (18R) and $\gamma_{1}$, $(2 \mathrm{H})$, is formed depending upon the composition ( $\mathrm{Al}$ and $\mathrm{Mn}$ contents) of the alloys [3]. While $\beta_{1}$ martensite is predominant at lower aluminum contents, $\gamma_{1}{ }^{\prime}$ martensite is prevalent at higher Al concentrations. On the other hand, both $\beta_{1}{ }^{\prime}$ and $\gamma_{1}$ ' martensites co-exist in the intermediate concentration range [4]. Manganese addition to binary $\mathrm{Cu}-\mathrm{Al}$ alloys has been found to stabilize the BCC phase, i.e. depressing the temperature range of stability of the $\beta$ phase to lower temperatures, and widening the range of composition over which they exist. It brings about enhanced ductility of the alloys by decreasing the degree of order [5]. It has been found that the transformation temperatures of these alloys are also highly sensitive to the variation in $\mathrm{Al}$ and $\mathrm{Mn}$ concentration. Both $\mathrm{Al}$ and $\mathrm{Mn}$ decrease the transformation temperatures of the alloys [6].

a e-mail: vsampatheitm.ac.in

This is an Open Access article distributed under the terms of the Creative Commons Attribution-Noncommercial License (http://creativecommons.org/licenses/by-nc/3.0/), which permits unrestricted use, distribution, and reproduction in any noncommercial medium, provided the original work is properly cited. 
Unlike binary $\mathrm{Cu}-\mathrm{Al}$ alloys, ternary $\mathrm{Cu}-\mathrm{Al}-\mathrm{Mn}$ alloys show good strain recovery by shape memory as well as superelastic effect. These days there are many applications, wherein SMAs with enhanced shape memory effect and superelastic properties are required. In the present study, the effect of minor additions of grain refiners, namely $\mathrm{B}$ and $\mathrm{Zr}$, on the transformation temperatures, shape memory effect (SME) and superelasticity (SE) of $\mathrm{Cu}-\mathrm{Al}-\mathrm{Mn}$ alloys are investigated in detail and the results are presented. The study brings to light that that B acts as a good grain refiner, resulting in a reduction of about $80 \%$ in grain size, while $\mathrm{Zr}$ has only a marginal effect on the grain size. Boron addition increases the transformation temperatures by $\sim 10^{\circ} \mathrm{C}$. In addition, it decreases the strain recovery by shape memory effect by $4 \%$, and that by superelasticity by about $2 \%$.

\section{Experimental procedure}

\subsection{Alloy ingot preparation}

A copper alloy with 12.5 wt.\% of $\mathrm{Al}$ and 5 wt.\% of $\mathrm{Mn}$ as alloying additions was prepared by ingot metallurgy by adding different amounts of boron or zirconium( 0.05 to $0.2 \mathrm{wt} . \%)$ to it. The ingots weighing $500 \mathrm{~g}$ each were produced by melting together of pure $\mathrm{Cu}, \mathrm{Al}, \mathrm{Mn}$ and the master alloy of boron or the master alloy of zirconium in an induction furnace under an argon atmosphere. The $\mathrm{Al}$ as well as Mn content was maintained constant, while that of $\mathrm{B}$ or $\mathrm{Zr}$ was varied in each of the ingots produced. Ingots measuring $150 \mathrm{~mm} \times 100 \mathrm{~mm} \times 5 \mathrm{~mm}$ were produced by pouring the liquid alloy into a cast iron mould. The ingots were heated to the austenitizing/betatizing temperature $\left(900^{\circ} \mathrm{C}\right)$ and homogenized for $6 \mathrm{~h}$ under an argon atmosphere. The composition analysis of the alloys was carried out using a Perkin-Elmer integrally coupled plasma-optical emission spectrophotometer (ICP-OES).

\subsection{Thermomechanical treatment and characterization studies}

The samples of the homogenized alloy were rolled at $900^{\circ} \mathrm{C}$ from a thickness of $5 \mathrm{~mm}$ down to $1 \mathrm{~mm}$. They were then betatized at $900^{\circ} \mathrm{C}$ for $30 \mathrm{~min}$. and step quenched into a hot water bath $\left(\sim 100^{\circ} \mathrm{C}\right)$. This was followed by quenching them into a water bath at room temperature $\left(\sim 30^{\circ} \mathrm{C}\right)$. Step quenching was beneficial in getting rid of the formation of quench cracks and the pinning of martensitic plates by excess dislocations trapped in on quenching from high temperature [7, 8]. Optical micrographs of the alloys were obtained so as to study the morphology of the martensite and the precipitate particles formed. A Netzsch 204 differential scanning calorimeter (DSC) was used to determine transformation temperatures by adopting a heating / cooling rate of $10^{\circ} \mathrm{C} / \mathrm{min}$.

The grain size of the alloy specimens with different amounts of $\mathrm{B}$ and $\mathrm{Zr}$ addition was measured by optical microscopy at a magnification of 100X. The grain size was determined by the Biovismet 4.1 Mediimage analyzing system making use of the planimetry method, and the Zwick Roell ENTEC C.A.M.S. testing system making use of the template method (ASTM E 112-96).

The strain recovery by SME was determined by carrying out bend tests on $1 \mathrm{~mm}$ thick specimens and measuring the initial and final bend angles just before loading and after unloading, and similarly the bend angles before and after heating. The strain recovery by SE of the alloys was determined by cyclic tensile test of the specimens in the austenitic phase of the alloys.

\section{Results and discussions}

\subsection{Characteristic transformation temperatures and microstructures}

The chemical composition of the alloy samples and the corresponding transformation temperatures are presented in Table 1. Boron or zirconium was added to alloys maintaining the same base compositions, i.e. Cu-12.5 wt.\%Al-5 wt.\%Mn (with boron addition CAMB 1-4 and with zirconium addition CAMZr 1-4). The variation of transformation temperatures with the grain refining additions is plotted in Fig. 1. As can be observed, boron causes an increase in the transformation temperatures of up to $15^{\circ} \mathrm{C}$. The optical micrographs of the alloy samples with the grain refining additions are given in Fig. 2 (a) and (b). The grain 
refinement obtained with boron and zirconium addition can be clearly seen from the micrographs. The optical micrographs of the base alloy with $12.5 \mathrm{wt} \% \mathrm{Al}$ and $5 \mathrm{wt} \% \mathrm{Mn}$ and with boron additions (0.050.19 wt.\%) are given in Fig. 2(a). These alloys exhibit martensite in their microstructure at room temperature as is evidenced by the $\mathrm{M}_{\mathrm{s}}$ and $\mathrm{M}_{\mathrm{f}}$ temperatures lying around room temperature $\left(\sim 30^{\circ} \mathrm{C}\right)$. The optical micrographs of the base alloy with $12.5 \mathrm{wt} . \% \mathrm{Al}$ and $5 \mathrm{wt} . \% \mathrm{Mn}$ and with zirconium additions (0.05-0.2 wt.\%) are given in Fig. 2(b). The formation of a large amount of precipitate particles can be observed in these alloys.

The addition of boron and zirconium leads to the formation of fine intermetallic particles, which alter the base chemical composition of the matrix either by increasing or decreasing the aluminum and manganese contents. It thus results in the transformation temperatures of the alloy being modified. As can clearly be seen from the micrographs, boron acts as a good grain refiner. Table 2 gives the grain size values obtained with the addition of boron and zirconium. Fig. 3 shows the variation of grain size with variation in boron and zirconium addition. The grain size decreases from $460 \mu \mathrm{m}$ to $97 \mu \mathrm{m}$ with boron addition, i.e. a grain size reduction of $\sim 80 \%$ was obtained. The grain size decreases from $460 \mu \mathrm{m}$ to $340 \mu \mathrm{m}$ with zirconium addition, i.e. a grain size reduction of $\sim 25 \%$ was obtained.

From the optical micrographs of the samples it can be observed that the addition of zirconium results in a large amount of precipitate particles compared with those for boron additions. From the spot EDAX analysis of these intermetallic particles it was found that there is an excess amount of aluminum (increasing from $12.5 \mathrm{wt} . \%$ to $13.84 \mathrm{wt} . \%$ ) in the precipitate, while the concentration of manganese in the precipitate is less (decreasing from $5 \mathrm{wt} \%$ to $4.12 \mathrm{wt} \%$ ). Correspondingly, there is a decrease in the amount of aluminum and an increase in the amount of manganese in the matrix. The overall effect was that not much variation in the transformation temperatures was observed with the addition of zirconium.

Table 1. Chemical composition and transformation temperatures of $\mathrm{Cu}-\mathrm{Al}-\mathrm{Mn} \mathrm{SMAs}$ with boron and zirconium addition.

\begin{tabular}{ccccccccc}
\hline \multirow{2}{*}{$\begin{array}{c}\text { Alloy } \\
\text { ID }\end{array}$} & \multicolumn{3}{c}{ Chemical composition (wt.\%) } & \multicolumn{3}{c}{ Transformation temperature $\left({ }^{\circ} \mathrm{C}\right)$} \\
\cline { 2 - 9 } & $\mathrm{Cu}$ & $\mathrm{Al}$ & $\mathrm{Mn}$ & $\begin{array}{c}\text { Grain } \\
\text { refiner }\end{array}$ & $\mathrm{M}_{\mathrm{f}}$ & $\mathrm{M}_{\mathrm{s}}$ & $\mathrm{A}_{\mathrm{s}}$ & $\mathrm{A}_{\mathrm{f}}$ \\
\hline CAM & 82.08 & 12.45 & 5.47 & $\begin{array}{c}- \\
\text { Boron }\end{array}$ & 16.4 & 39.5 & 42.1 & 61.6 \\
CAMB 1 & 82.45 & 12.50 & 5.00 & 0.05 & 24.3 & 41.6 & 50.5 & 75.4 \\
CAMB 2 & 82.42 & 12.49 & 4.97 & 0.12 & 28.6 & 52.1 & 62.2 & 81.6 \\
CAMB 3 & 82.25 & 12.50 & 5.10 & 0.15 & 30.1 & 52.7 & 65.3 & 86.1 \\
CAMB 4 & 82.31 & 12.50 & 5.00 & 0.19 & 34.5 & 61.2 & 72.3 & 89.2 \\
& & & & Zirconium & & & & \\
CAMZr 1 & 82.05 & 12.50 & 5.40 & 0.05 & 17.5 & 38.1 & 41.5 & 62.3 \\
CAMZr 2 & 82.18 & 12.70 & 5.00 & 0.12 & 16.0 & 36.3 & 42.6 & 60.1 \\
CAMZr 3 & 82.23 & 12.60 & 5.00 & 0.17 & 18.2 & 35.7 & 39.2 & 61.0 \\
CAMZr 4 & 81.70 & 12.50 & 5.60 & 0.20 & 20.4 & 39.0 & 40.8 & 63.6 \\
\hline
\end{tabular}
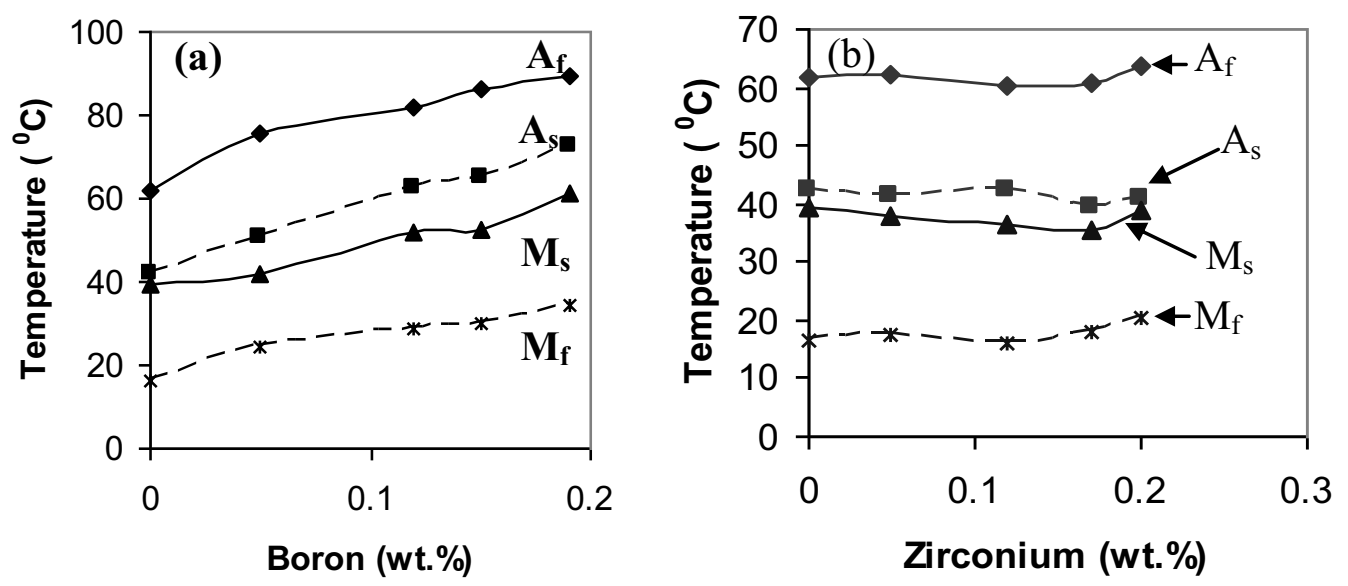

Fig. 1. Variation of transformation temperatures: (a) with boron addition (b) with zirconium addition 

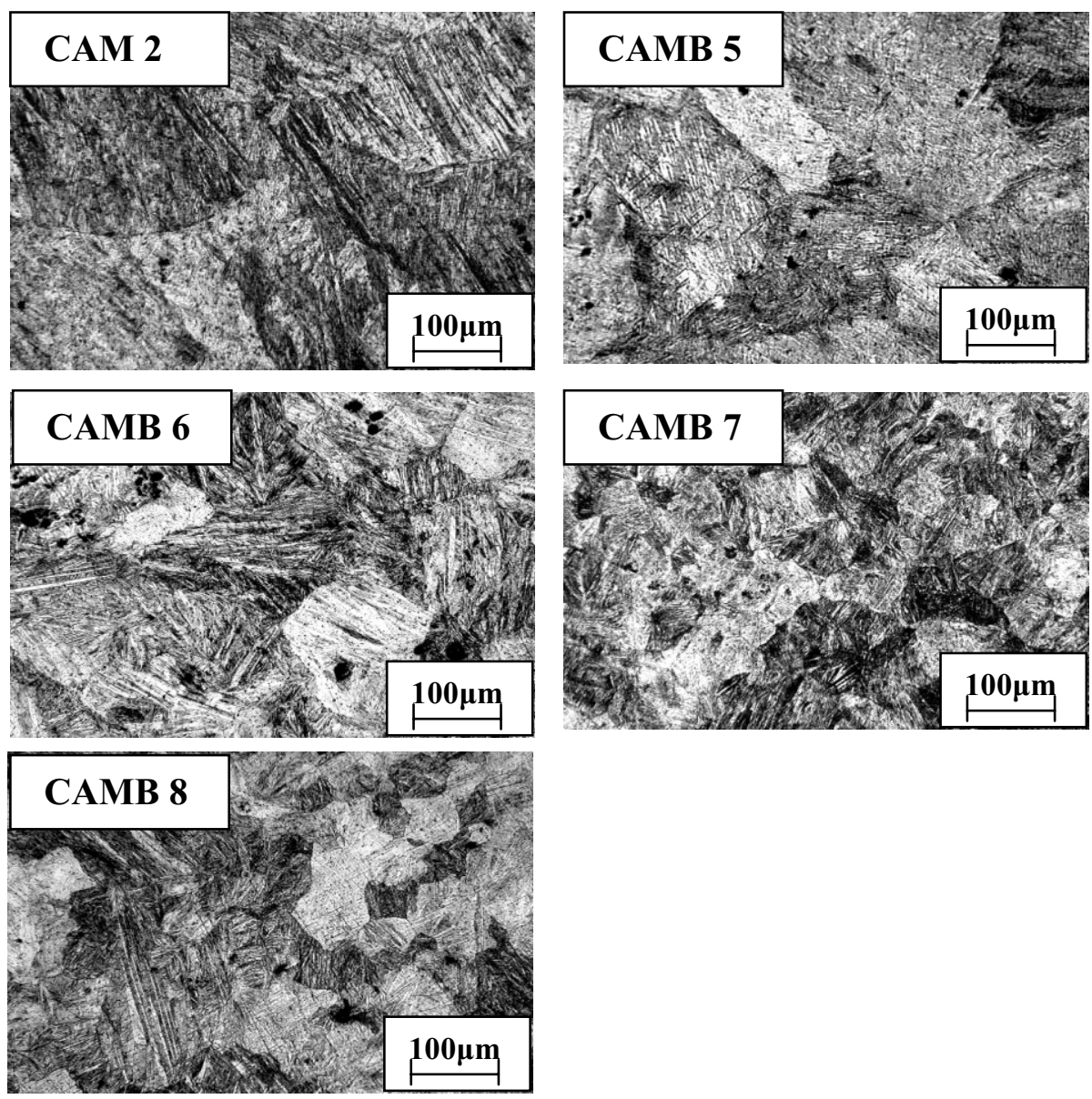

Fig. 2(a).Optical micrographs of the base alloy with $12.5 \mathrm{wt} \% \mathrm{Al}$ and $5 \mathrm{wt} . \% \mathrm{Mn}$ with boron addition.
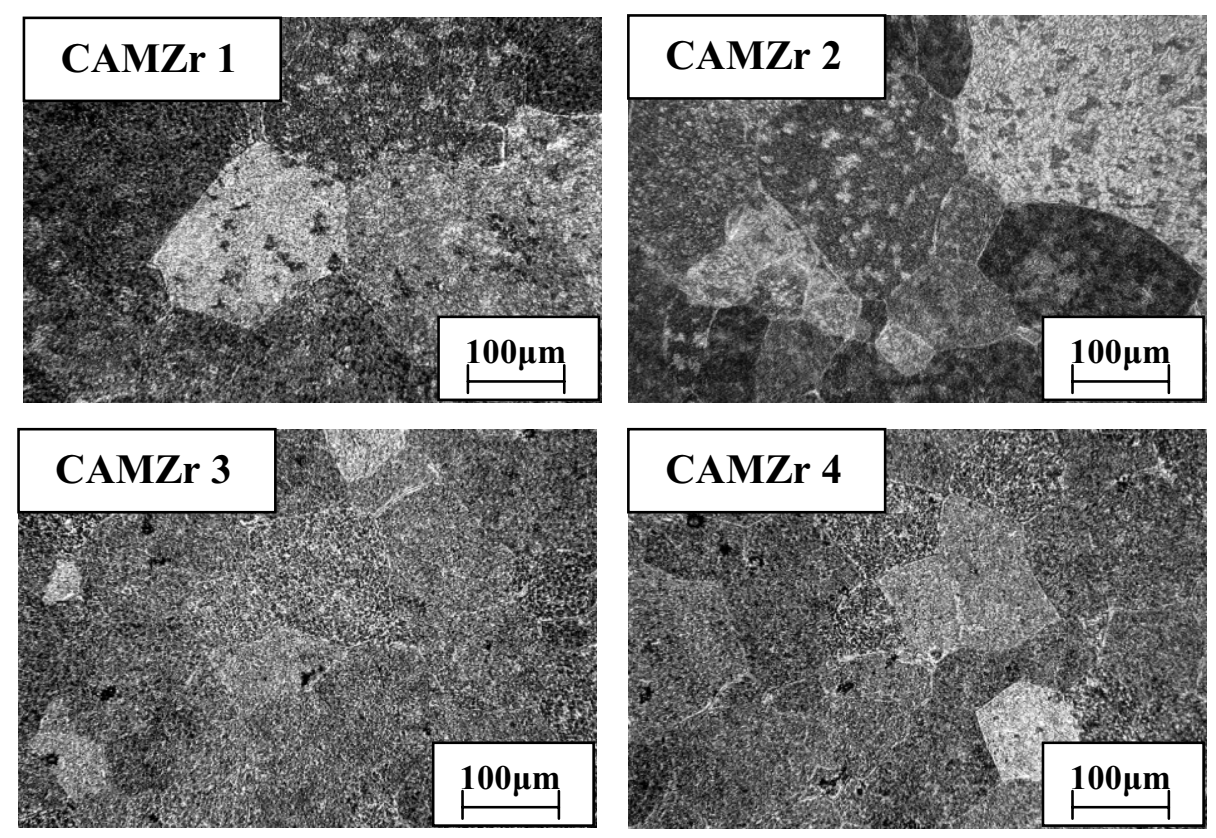

Fig. 2(b).Optical micrographs of the base alloy with 12.5 wt.\% $\mathrm{Al}$ and $5 \mathrm{wt} . \% \mathrm{Mn}$ with zirconium addition. 

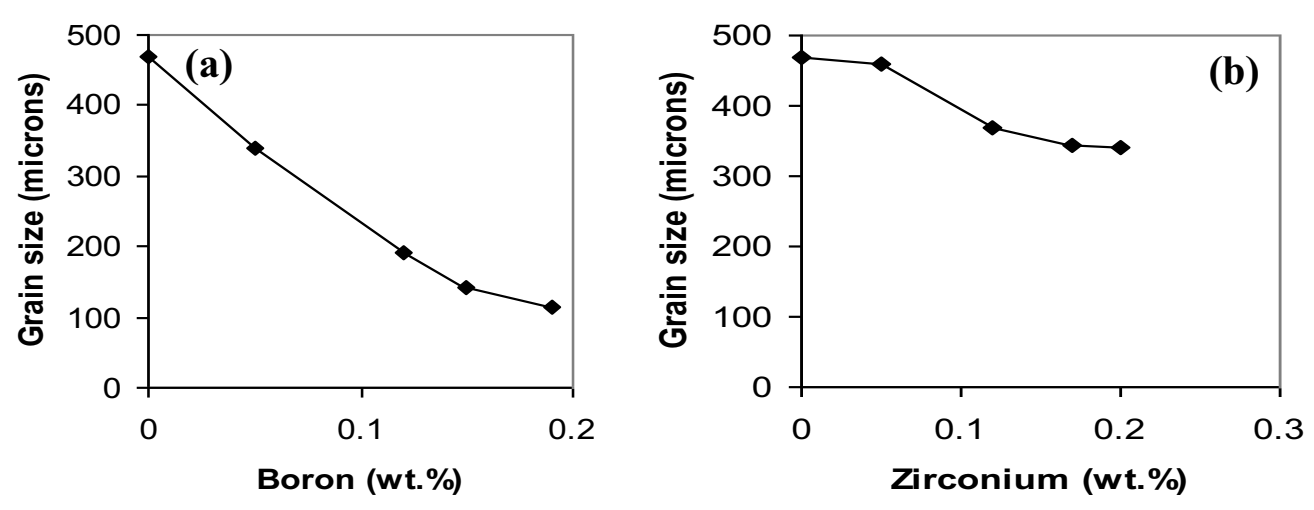

Fig. 3. Variation of grain size: (a) with boron addition (b) with zirconium addition

\subsection{Shape memory effect (SME)}

The magnitude of strain recovery by SME of the different alloy compositions determined by bend test is given in Table 2. The variation of strain recovery by SME with the grain refining additions is given in Fig. 4. It can be observed the strain recovery by SME decreases by $\sim 10 \%$ by boron addition. There is no appreciable change in the strain recovery by SME by the addition of zirconium. The zirconium addition marginally decreases the strain recovery by SME $(2-4 \%)$. The extent of strain recovery by SME depends on the amount of martensite transformed, the size and morphology of the plates and the nature and amount of defects present in the alloys. As the grain size decreases, the thickness of the martensite plates decreases. As a result, the martensite transformation by plate movement and variant reorientation become more difficult. In addition, the intermetallic/precipitate particles formed due to grain refining additions also hamper the easy transformation of the martensite due to pinning effect. All these factors lead to a decrease in the strain recovery by SME with the decrease in grain size [9].

\subsection{Superelastic effect(SE)}

The tension tests were carried out as per ASTM E8M-04 standard on an Instron tensile testing machine in the austenitic phase of the alloys $\left(\mathrm{A}_{\mathrm{f}}+30^{\circ} \mathrm{C}\right)$. Fig. 5 gives the stress-strain curves for alloy CAMB 3 at $116^{\circ} \mathrm{C}$, at which temperature the alloy is fully austenitic. The superelastic strain is given by $\varepsilon_{\mathrm{SE}}=\varepsilon_{\mathrm{T}}-\varepsilon_{\mathrm{e}}-\varepsilon_{\mathrm{r}}$ , where $\varepsilon_{\mathrm{T}}$ refers to the total strain, $\varepsilon_{\mathrm{e}}$ the elastic strain of the material, and $\varepsilon_{\mathrm{r}}$ the residual strain remaining in the material in the fully unloaded condition. Table 2 gives the superelasticity of all the grain refined alloys. The variation of superelastic strain with boron and zirconium addition is plotted in Fig. 6. As can be observed, the superelastic strain decreases with increasing grain refining addition and decreasing grain size. As the grain size decreases, the strain constraints increase and the width of martensite plates decrease. As a result, a higher stress is required to form stress induced martensite, leading to reduced recoverable strain [10]. Hence SME and SE decrease with reduced grain size. 
Table 2. Grain size, strain recovery by SME and superelasticity of $\mathrm{Cu}-\mathrm{Al}-\mathrm{Mn}$ SMAs with boron and zirconium addition

\begin{tabular}{|c|c|c|c|c|c|c|c|}
\hline \multirow[b]{2}{*}{$\begin{array}{l}\text { Alloy } \\
\text { ID }\end{array}$} & \multicolumn{4}{|c|}{ Chemical composition (wt.\%) } & \multirow[b]{2}{*}{$\begin{array}{l}\text { Grain Size } \\
\quad(\mu \mathrm{m})\end{array}$} & \multirow{2}{*}{$\begin{array}{c}\text { Strain } \\
\text { recovery } \\
\text { by SME } \\
(\%)\end{array}$} & \multirow{2}{*}{$\begin{array}{c}\text { Super- } \\
\text { elasticity } \\
(\%)\end{array}$} \\
\hline & $\mathrm{Cu}$ & $\mathrm{Al}$ & $\mathrm{Mn}$ & $\begin{array}{l}\text { Grain } \\
\text { refiner }\end{array}$ & & & \\
\hline CAM & 82.08 & 12.45 & 5.47 & - & 468 & 94 & 5 \\
\hline & & & & Boron & & & \\
\hline CAMB 1 & 82.45 & 12.50 & 5.00 & 0.05 & 340 & 94 & 4.5 \\
\hline CAMB 2 & 82.42 & 12.49 & 4.97 & 0.12 & 190 & 77 & 3.8 \\
\hline CAMB 3 & 82.25 & 12.50 & 5.10 & 0.15 & 143 & 75 & 4 \\
\hline CAMB 4 & 82.31 & 12.50 & 5.00 & 0.19 & 114 & 78 & 3 \\
\hline & & & & Zirconium & & & \\
\hline CAMZr 1 & 82.05 & CAMZr 1 & 82.05 & CAMZr 1 & 459 & 94 & 5 \\
\hline CAMZr 2 & 82.18 & CAMZr 2 & 82.18 & CAMZr 2 & 369 & 81 & 3.3 \\
\hline CAMZr 3 & 82.23 & CAMZr 3 & 82.23 & CAMZr 3 & 343 & 90 & 3 \\
\hline CAMZr 4 & 81.70 & CAMZr 4 & 81.70 & CAMZr 4 & 340 & 91 & 3 \\
\hline
\end{tabular}
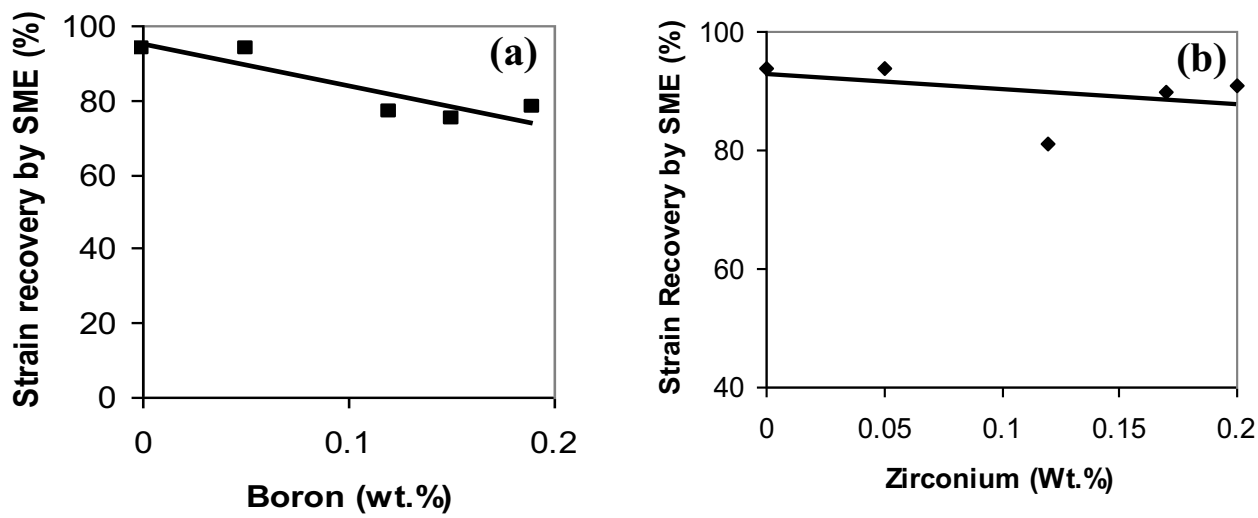

Fig. 4. Variation of strain recovery by SME: (a) with boron addition (b) with zirconium addition

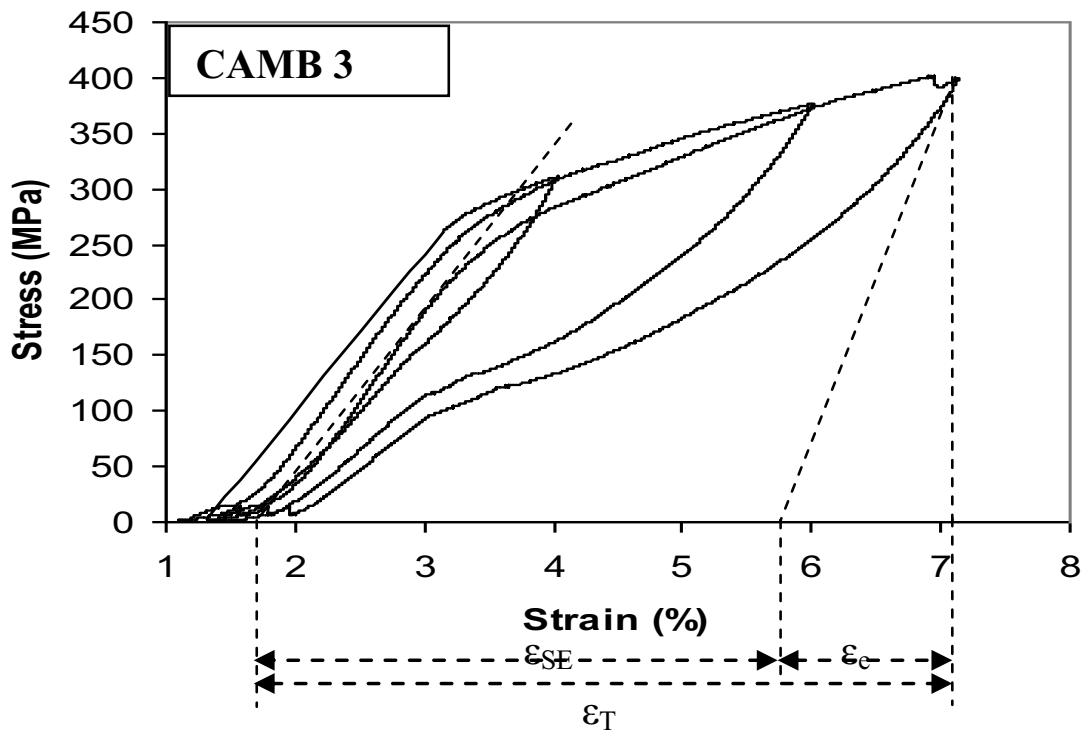

Fig. 5. Stress-strain curve for the alloy CAMB 3. 

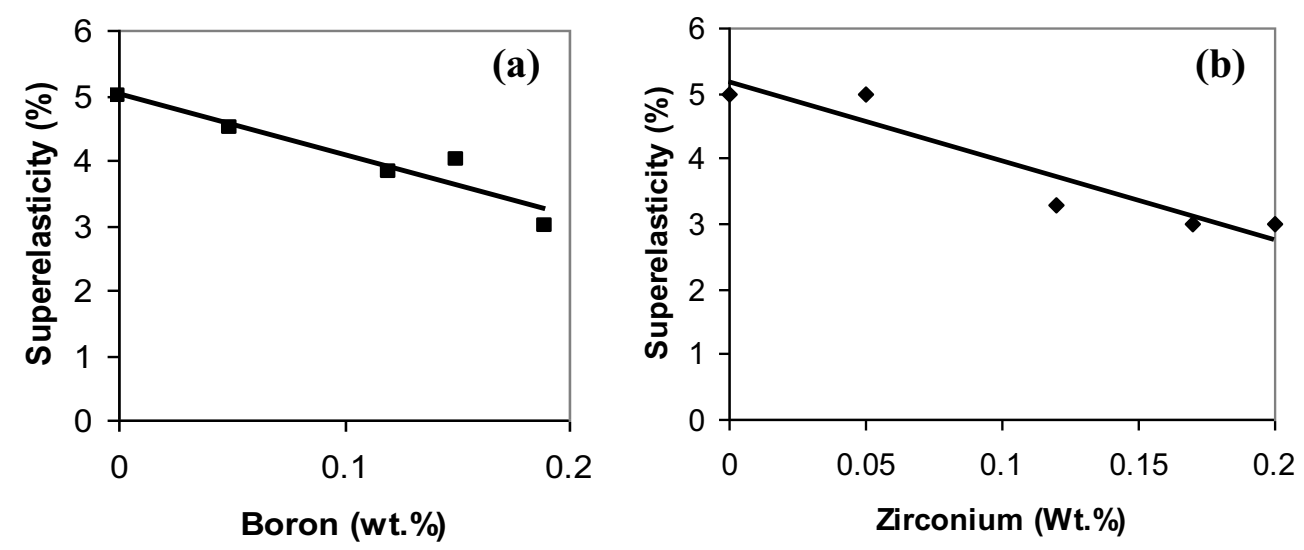

Fig. 6. Variation in superelasticity (a) with the boron (b) with zirconium addition

\section{Conclusions}

(i) Boron acts as a good grain refiner, wherein a grain refinement of $460 \mu \mathrm{m}$ to $97 \mu \mathrm{m}$ was obtained, which means there is a reduction of about $80 \%$. No appreciable grain refinement was obtained with the addition of $\mathrm{Zr}$. The grain size decrease obtained by the addition of $\mathrm{Zr}$ was $460 \mu \mathrm{m}$ to $340 \mu \mathrm{m}$, i.e. a reduction of about $25 \%$. The grain refinement is due to the formation of secondary phases and also due to the dissolution of the elements in the alloy matrix.

(ii) The addition of $\mathrm{B}$ increases the transformation temperatures by about $10^{\circ} \mathrm{C}$. The addition of zirconium increases the transformation temperatures only slightly $\sim 4^{\circ} \mathrm{C}$. The change in the transformation temperatures is attributed to the formation of precipitates, which leads to a change in the composition of the parent austenitic phase.

(iii) There is a decrease in the strain recovery by SME due to grain refinement, a decrease of the order of $4-6 \%$ was observed.

(iv) The superelasticity of the alloys decreases with a decrease in grain size. The grain refining additions $\mathrm{B}$ and $\mathrm{Zr}$ decrease the superelasticity by about $2 \%$. With a reduction in grain size, the strain constraints increase and the width of martensite plates decrease. A higher stress is therefore required to form stress induced martensite. It also reduces the recoverable strain. Hence SME and SE decrease with grain refinement.

\section{References}

[1] Y. Sutou, T. Omori, J.J. Wang, R. Kainuma, K.Ishida, Mater. Sci. Eng. A 378 (2004) 278-282.

[2] Y. Sutou, R. Kainuma, K. Ishida, Mater. Sci. Eng. A 273-275 (1999) 375-379.

[3] R. Kainuma, S. Takahashi, K. Ishida, Metal. Mater. Trans. A 27A (1996) 2187-2195.

[4] U.S.Mallik, V.Sampath, J. Alloys Compd. 459 (14 July 2008) 142-147.

[5] R.Kainuma, N.Satoh, X.J.Liu, I.Ohnuma, K.Ishida, J. Alloys Compd. 266 (1998) 191 200.

[6] U.S.Mallik, V.Sampath, Mater. Sci. Eng. A 478 (2008) 48-55.

[7] C.Lopez del Castillo, M.L.Blazquez, C.Gomez, B.G.Mellor, N.de Diego, J.del Rio, J. Mater. Sci. 23 (1988) 3379-3382.

[8] S.W.Husain, P.C.Clapp, J. Mater. Sci. 22 (1987) 2351-2356.

[9] M.R.Zhang, D.Z.Yang, T.Tadaki and Y.Hirotsu, Scripta Materialia 36 No.2 (1997) 247-252.

[10] Sutou,Y., T.Omori, K.Yamauchi, N.Ono, R.Kainuma and K.Ishida, Acta Materialia 53 (2005) 4121-4133. 